East African Medical Journal Vol. 77 No. 10 October 2000

NEURAL TUMOURS OF THE HEAD AND NECK

M. L. Chindia, BDS, MSc, FFDRCSI and E. Dimba, BDS, Department of Oral and Maxillofacial Surgery and Oral Pathology/Oral Medicine, Faculty of Dental Sciences, University of Nairobi, P O. Box 19676, Nairobi, Kenya.

Request for reprints to: Dr. M. L. Chindia, Faculty of Dental Sciences, University of Nairobi, P.O. Box 19676, Nairobi, Kenya.

\title{
NEURAL TUMOURS OF THE HEAD AND NECK
}

\author{
M. L. CHINDIA and E. DIMBA
}

\begin{abstract}
Objective: To document the pattern of occurrence of all primary neural tumours arising in the neck and craniofacial region over the period 1982 to 1991.

Design: A retrospective study.

Setting: Cancer Registry, Nairobi, Kenya.

Results: Out of the 289 cases who were identified to have had whole body neural tumours, $225(77.8 \%)$ had the lesions distributed in the neck and craniofacial area. While $80 \%$ of the neoplasms located in this region were retinoblastomas (mainly occurring in the age group 0 to 4 years), other lesion types occurred in small numbers thus: neurofibromas comprised 12.4\%, Schwannomas four per cent, neuroblastomas and neuromas each $0.4 \%$; and extracranial gliomas $2.7 \%$. Overall, the male to female ratio was $1: 1$ and the site distribution revealed that over $90 \%$ of the lesions afflicted the upper face.

Conclusion: Neural tumours of the neck and craniofacial region appear generally rare in this population as has been shown elsewhere.
\end{abstract}

\section{INTRODUCTION}

Tumours arising from peripheral nerves in the oral and paraoral tissues are not common(1). These neoplasms do, however, merit special attention because even histologically benign lesions may be grossly disabling or even fatal owing to the infiltration and/or compression of vital structures. Of special importance is the fact that some malignant neural tumours may originate in previously benign lesions of neurofibromatosis.

It is also worthy of note that malignant neoplasms arising from nerve tissue, specifically from nerve sheath cells, are extremely rare lesions in and about the oral cavity(2). Indeed, on a worldwide basis, comprehensive series of the epidemiology of neural tumours of the head and neck region in general are few. In this study we present the pattern of occurrence of neural tumours of the head and neck area over a ten-year period.

\section{MATERIALS AND METHODS}

The Cancer Registry of the Kenyatta National Hospital (KNH) in Nairobi, Kenya was established in 1969 by the International Agency for Research on Cancer(3). This registry was established within the department of Human Pathology,
Faculty of Medicine of the University of Nairobi. KNH has remained the major teaching and referral hospital in the country whose population is 28 million people. Over the years, specimens for histopathological analysis have largely been sourced from various regions countrywide.

A manual inspection of the Cancer Registry was performed to analyse the type and pattern of occurrence of neural tumours of the head and neck region over the period 1982 to 1991 inclusive. No attempt was made to evaluate the accuracy status of this registry since the specialists who were involved in its inception were still at the department and, therefore, the consistency of documentation was assumed.

\section{RESULTS}

Over the 10-year period, 289 cases were identified to have had whole body neural tumours out of whom $225(77.8 \%$ ) cases had these lesions distributed in the neck and craniofacial area. Eighty per cent of the subjects had retinoblastomas which largely occurred in the age range of up to four years. The distribution of the tumours according to the age groups is presented in Table 1 . While the overall sex distribution was $1: 1$, it was difficult to establish definite patterns of the age distribution for the small numbers of the individual lesion types recorded. The lesion type distribution according to sex is shown in Table 2. 
Table 1

Tumour distribution according to age groups

\begin{tabular}{rcccccc}
\hline \multirow{2}{*}{$\begin{array}{l}\text { Age group } \\
\text { in years }\end{array}$} & R/B & N/F & SCH & NEU & N/B & GL \\
\hline $0-4$ & 161 & 1 & - & - & - & - \\
$5-9$ & 19 & 4 & 1 & 1 & - & 1 \\
$10-14$ & - & 4 & - & - & - & 1 \\
$15-19$ & - & 4 & 4 & - & - & 1 \\
$20-24$ & - & 3 & 1 & - & - & 1 \\
$25-29$ & - & 3 & - & - & - & - \\
$30-34$ & - & 1 & - & - & - & - \\
Over 35 & - & 6 & 3 & - & 1 & 2 \\
\hline Total & 180 & 28 & 9 & 1 & 1 & 6 \\
\hline
\end{tabular}

Key:

$\mathrm{R} / \mathrm{B}=$ Retinoblastoma

$\mathrm{M} / \mathrm{B}=$ Neuroblastoma

$\mathrm{NEU}=$ Neuroma

\section{$\mathrm{SCH}=$ Schwannoma}

$\mathrm{N} / \mathrm{F}=$ Neurofibroma

GLI = Glioma

Table 2

Distribution of the neural tumours according to sex

\begin{tabular}{lrc}
\hline Tumour & Male & Female \\
\hline Retinoblastoma & 98 & 82 \\
Neurofibroma & 11 & 17 \\
Schwannoma & 6 & 3 \\
Neuroma & 1 & 0 \\
Neuroblastoma & 1 & 0 \\
Glioma & 3 & 3 \\
\hline Total & 120 & 105 \\
\hline
\end{tabular}

Table 3

Tumour distribution according to site

\begin{tabular}{|c|c|c|c|c|c|}
\hline \multirow[t]{2}{*}{ Tumour } & \multicolumn{5}{|c|}{ Site } \\
\hline & $\begin{array}{l}\text { Upper } \\
\text { face }\end{array}$ & $\begin{array}{l}\text { Mid } \\
\text { face }\end{array}$ & $\begin{array}{r}\text { Lower } \\
\text { face }\end{array}$ & Neck & Generalised \\
\hline
\end{tabular}

\begin{tabular}{lrrrrr}
\hline Retinoblastoma & 180 & - & - & - & - \\
Neurofibroma & 12 & - & 3 & 10 & 3 \\
Schwannoma & 4 & 1 & - & 4 & - \\
Neuroma & 1 & - & - & - & - \\
Neuroblastoma & 1 & - & - & - & - \\
Glioma & 6 & - & - & - & - \\
\hline Total & 204 & 1 & 3 & 14 & 3 \\
\hline
\end{tabular}

Notably, only small numbers of individual lesion types were encountered thus: neurofibromas constituted $12.4 \%$, Schwannomas $4 \%$, neuroblastomas and neuromas each $0.4 \%$; and extracranial gliomas $2.7 \%$. The site distribution (Table 3 ) indicates that while over $90 \%$ of lesions were located in the upper face, only about $2 \%$ of the tumours occurred in the mid and lower faces combined. Only $6.2 \%$ of the neural tumours were located in the neck region.

\section{DISCUSSION}

Evidently, results of the current investigation indicate that both benign and malignant neoplasms arising from neural tissue are generally rare as has been shown elsewhere(1). However, it is important to note in these results that retinoblastoma(RB) appears to have been a particularly common lesion since over the ten-year period, an average of 18 cases were recorded annually. It is also of interest to note that this neoplasm occurred almost exclusively in cases aged below ten years. In view of the grave morbidity and high mortality associated with this neoplasm, accurate documentation of its pattern of occurrence must be encouraged. Retinoblastoma, derived from retinal neuroepithelial progenitor cells, is the most common intraocular malignancy of childhood(6). Apparently, the disease has no significant differences in the way it afflicts males and females(7). However, a male/ female ration of 1.4:1 has been shown in one study(8). According to the International Classification of Diseases for Oncology (WHO, 1990), there are two types of retinoblastoma: the differentiated (D-type) and the undifferentiated (U-type). The D-type of retinoblastoma is found more commonly in younger infants less than one year, but the U-type found more frequently in children aged two to four years(9). Notably, only a few cases of retinoblastoma in older children ( $>10$ years of age) have been reported and the clinical diagnosis may be difficult(10). However, cytological aspiration can categorically diagnose suspected intraocular tumours of older children in whom clinical and non-invasive investigations have failed to establish the diagnosis.

Except for the neurofibroma, the distribution according to the age groups of all the other lesion types including the Schwannoma, neuroma, neuroblastoma and glioma appears to have been particularly sporadic. As for the glioma which was shown to have been diagnosed almost consistently over the age groups, it was difficult to ascertain the exact extracranial locations of the lesions. Admittedly, this is a limitation inherent in most studies of this nature.

Notwithstanding the small numbers of the various neoplasm types, the overall picture appears to be that of a slight preponderance of the occurrence of neural tumours among males over females (Table 2). It is also notable that the majority of these neoplasms generally appear to occur in much younger age groups. The socio-economic implications of such findings should be of interest to all health planners and providers since cancer affliction at an early age may often require special considerations in the overall management of patients.

Interestingly, the occurrence of the various tumour types in this study indicates that hardly any diagnosis of the sarcomas of nerve tissue was made over the ten-year period. In diverse publications, sarcomas arising from Schwann cells or perineural fibroblasts have been termed malignant Schwannomas (neurilemmomas), neurogenic sarcomas and neurofibrosarcomas(4).

Perhaps the rarity of these neoplasms in diverse populations may also be exemplified by the current study. As a matter of fact, for many years the surgical pathologist has been frustrated in the attempt to describe and classify sarcomas of the somatic soft tissue(5). However, utilisation 
of the current advances in tissue analysis may rapidly facilitate exact characterisation and classification of many of these lesions.

In view of the fact that retrospective studies may yield deficient information on crucial clinical and histopathological detail, it is noted that prospective analysis of disease patterns and their characterisation may offer the best records upon which management planning can best be made. Based on the findings of the current study, it is recommended that the Cancer Registry at the $\mathrm{KNH}$ will need immediate revamping and modernisation since it is a national asset.

\section{ACKNOWLEDGEMENTS}

We are most grateful to the Chairman, Department of Human Pathology, University of Nairobi, for the permission to execute this study. We are also greatly indebted to Drs. C. Ngovo, S. Patel and M.W. Muriithi for active participation in data collection. Finally, we are most thankful to Miss Imbayi Carolyne for secretarial services.

\section{REFERENCES}

1. Wright, BA and Jackson, D. Neural Tumours of the Oral Cavity. Oral Surg. 1980; 49:509-5.
2. Shafer W.G., Hine M.K., Levy B.M. and Tomich C.E. Benign and Malignant Tumours of the Oral Cavity. In: Shafer W.G., Hine M.K. and Levy B.M. eds. A Textbook of Oral Pathology, 4th Edition; Philadelphia. WB. Saunders 1983; pp86-229.

3. WHO, EPI/8.Sta/9: Cancer Registration in Africa. Nairobi, 1969.

4. D'Agostino A.N., Soule E.H. and Miller R.H. Sarcomas of the peripheral nerves and somatic soft tissues associated with multiple neurofibromatosis (von Recklinghausen's Disease). Cancer 1963; 16:11015-1027.

5. D'Agostino A.N., Soule E.H. and Miller R.H. Primary malignant neoplasms of nerves (Malignant Neurilemommas) in patients without manifestations of multiple neurofibromatosis (von Recklinghausen's Disease). Cancer 1963; 16:1003-1014.

6. Madigan, M.C. and Penfold, P.L. Human retinoblastoma: A morphological study of apoptotic, leukocytic and vascular elements. Ultrastructural Pathology, 1997; 21:95-107.

7. Moll, A.C., Kuik, D.J. and Bouter L.M. et al. Incidence and survival of retinoblastoma in the Netherlands: a register based study 1862-1995. Brit. J. Ophthal. 1997; 81:559-562.

8. Sahu, S., Banavali, S.D. and Pai, S.K. et al. Retinoblastoma: problems and perspective from India. Paediat. Haemat. Oncol. 1998; 15:501-508.

9. Fujisawa, K., Ito, K., Imai, Y., Ito, H. and YamamotoM. Pathological and histological study on retinoblastoma. Kobe J. Med. Sci. 1998; 44:19-30.

10. Decaussin, M., Boran, M.D., Salle, M., Grange, I.D., Patricot, L.M. and Thivolet-Bejui, F. Cytological aspiration of intraocular retinoblastoma in an 11-year-old boy.Diagnostic Cytopathology, 1998; 19:190-193. 